\title{
A Parametric Investigation of the Steam Injection Gas Turbine System on a Cogeneration Plant
}

\author{
Phongthon Buntarikpornpant and Chittin Tangthieng* \\ Department of Mechanical Engineering, Faculty of Engineering, Chulalongkorn University, Pathumwan, \\ Bangkok, Thailand \\ *E-mail: qed690@yahoo.com (Corresponding author)
}

\begin{abstract}
The aim of this study is to conduct a parametric investigation of the steam injection gas turbine system by focusing on the effect of the steam mass flow rate on the energy transfer behaviors of a cogeneration plant. A thermodynamic model of two gas turbine cycles and one steam turbine cycle and a heat transfer model of the heat recovery steam generator are developed. A successive iteration is employed to solve a set of equations and obtain a converged solution. The result shows that by increasing the mass flow rate for the steam injection gas turbine system from 0 to $2 \mathrm{~kg} / \mathrm{s}$, the input energy rate from the fuel and the total electrical output power from the cogeneration plant are increased, resulting in an increase of the cogeneration electrical efficiency from $49.9 \%$ to $50.4 \%$. On the other hand, the output heat rate from the steam from the cogeneration plant is decreased, resulting in a decrease of the cogeneration heat efficiency from $8.5 \%$ to $5.4 \%$. Consequently, the primary energy saving of the cogeneration plant decreases from $16.6 \%$ to $14.9 \%$.
\end{abstract}

Keywords: Parametric study, cogeneration plant, steam injection gas turbine, primary energy saving.

ENGINEERING JOURNAL Volume 24 Issue 1

Received 5 April 2019

Accepted 13 November 2019

Published 8 February 2020

Online at http://www.engj.org/

DOI:10.4186/ej.2020.24.1.11 


\section{Introduction}

In Thailand, a small power producer (SPP) is a private power plant generating electric power with a capacity of 120-150 MW. It is usually located in an industrial estate widely established around the country. Based on the Thailand power development plan 20152036 (PDP2015), 4,084 MW generating capacity during 2015-2036 is produced from 66 SPP cogeneration power plants [1]. The main objectives of the implementation of the cogeneration plant are to promote the primary energy saving [2] and to reduce $\mathrm{CO}_{2}$ emission [3]. In some cases, the thermal energy storage system is utilized with the cogeneration plant in order to manage the peak demand [4]. To determine the efficiency of the cogeneration power plant, the primary energy saving (PES), is defined as the amount of the saving energy provided by the cogeneration plant compared to the energy provided by an individual electrical power plant and individual process-heating plant [5]. A complete procedure of how to calculate PES is given by a literature [6]. Since 2007, SPP cogeneration power plant is subsidized by Thai government under the feed-in tariff program if the value of PES is higher than $10 \%$ [7]. Thus, operating the cogeneration plant efficiently is an important factor for keeping PES higher than 10\%. The cogeneration plant efficiency can be improved by several methods such as waste heat utilization with a regenerator, single- or twinshaft configurations, low pressure intercooler, etc [8]. One of these methods is the steam injection gas turbine system or STIG system [9]. By recovering the waste heat from the gas turbine exhaust gas, the steam is generated thought a heat recovery steam generator or HRSG and injected into the combustion air after leaving the compressor. This will result in a higher mass flow rate, leading to the higher power output from the gas turbine. For a cogeneration plant, several studies of STIG system on the plant performance and operation are conducted. An investigation of the design-point performance characteristics of a cogeneration plant with different enhancements is presented [10]. The result indicates that the total electrical power and the thermal efficiency of the power plant increase as increasing amount of the steam injection. The operational experience of the implementation of STIG system on the cogeneration plant is reported on different aspects, including the plant efficiency, the operating cost, and the environmental impact [11]. The performance characteristics of the cogeneration cycle based upon practical performance constraints were investigated, with the result of higher electrical efficiency and lower cogeneration efficiency with increasing injected steam [12]. These studies are limited to the general performance or operational characteristics, but not including PES as a plantefficiency indicator. To extend an investigation of this topic, the effect of STIG system on PES of the cogeneration plant is presented in this study. A thermodynamic model of two gas turbine and one steam turbine cycles and a heat transfer model of HRSG are proposed to include the off-design conditions. The parametric study of the steam mass flow rate of the STIG system on the energy transfer behavior of a cogeneration plant is presented.

\section{Model Formulation}

A schematic diagram of the cogeneration plant under consideration with the relevant steam mass flow rates is depicted in Fig. 1. The plant consists of two gas turbine cycles and a steam turbine cycle. The HP and LP steam generated from HRSGs from two gas turbine cycles will be combined and sent to the HP and LP steam turbine, respectively. The exit steam from the HP steam turbine will be used as steam for STIG and external process steam. On the other hand, all exit LP steam from HRSG will be sent to the LP steam turbine condensed through a condenser. All condensate are divided for two gas turbine cycles and pumped back to both HRSGs. The detailed schematic diagram of the HRSG with the relevant steam mass flow rates is depicted in Fig. 2.

The HRGC consists of different parts: economizer (EC), evaporator (EV) and superheater $(\mathrm{SH})$. After LP hot water leaves the first LP economizer (LP EC1), some of it is extracted as the LP process hot water. The remaining steam flows to the second LP economizer (LP EC2), LP evaporator (LP EV) and LP superheater (LP $\mathrm{SH})$, respectively, to generate the LP steam. On the other hand, the HP steam will follow the similar pattern except only the HP steam is generated without the HP process hot water.

For the analysis of the gas turbine cycle, a basic Brayton cycle with a corresponding state depicted in Fig. 1 is employed as a thermodynamic model with technical data as shown in Table 1. To simplify the problem, the assumptions are made as follows: (i) air and exhaust gas can be assumed ideal gas; (ii) the properties of exhaust gas is considered to be identical to those of air; (iii) the specific heat of air is assumed constant at $750 \mathrm{~K}$; (iv) the specific heat of superheat steam is introduced to evaluate the enthalpy change of steam [13]. 


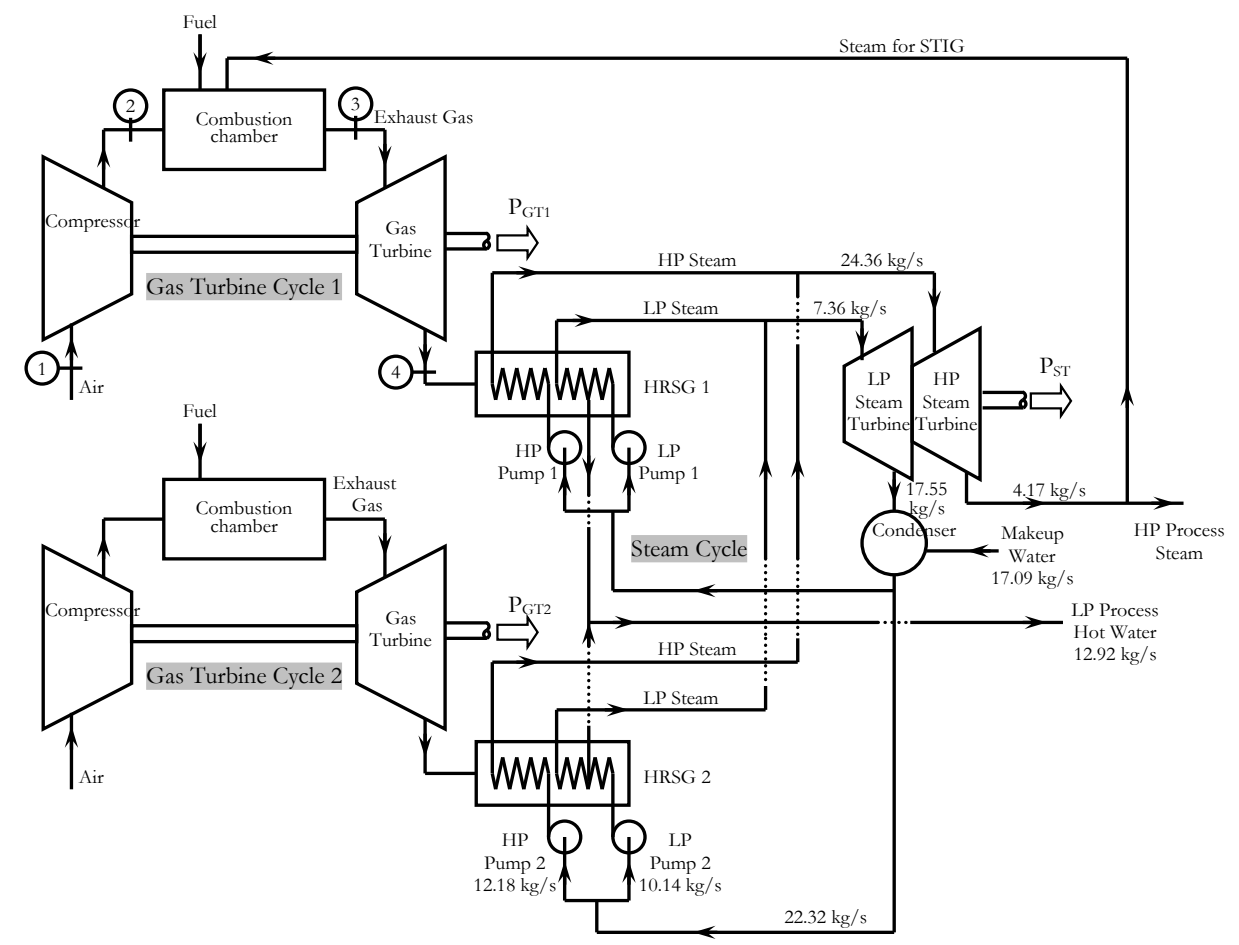

Fig. 1. A schematic diagram of the cogeneration plant under consideration.

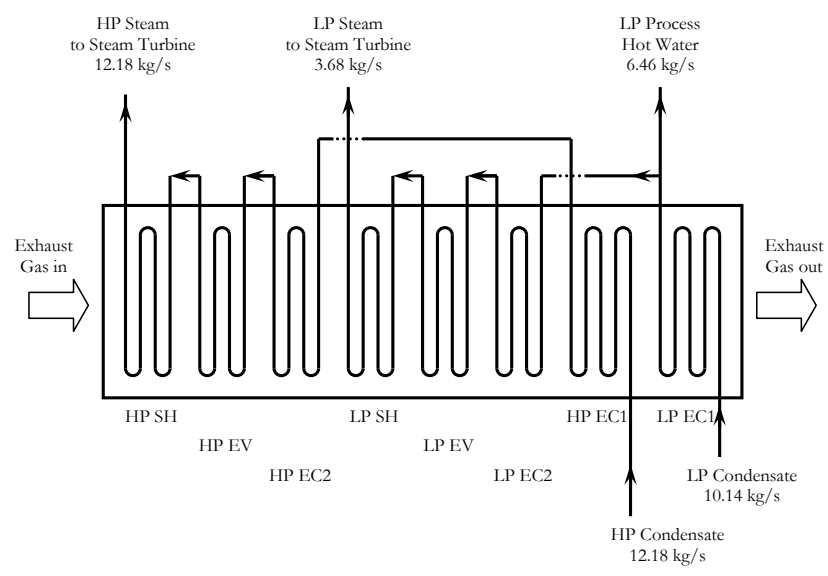

Fig. 2. A detailed schematic diagram of the HRSG.

Table 1. Technical data of the Brayton cycle.

\begin{tabular}{llccc}
\hline No. & \multicolumn{1}{c}{ Description } & Symbol & Value & Unit \\
\hline 1 & Air inlet temperature at the compressor & $T_{1}$ & 298.15 & $\mathrm{~K}$ \\
2 & Air inlet pressure at the compressor & $P A_{1}$ & 101.3 & $\mathrm{kPa}$ \\
3 & Air exit pressure at the compressor & $P A_{2}$ & 1,200 & $\mathrm{kPa}$ \\
4 & Air mass flow rate & $m_{a}$ & 115.39 & $\mathrm{~kg} / \mathrm{s}$ \\
5 & Lower heating value of the fuel & $L H V$ & 27.93 & $\mathrm{MJ} / \mathrm{scm}$ \\
6 & Maximum temperature at the turbine inlet & $T_{3}$ & 1,600 & $\mathrm{~K}$ \\
7 & Isentropic efficiency of the compressor & $\eta_{C}$ & 85 & $\%$ \\
8 & Isentropic efficiency of the turbine & $\eta_{G T}$ & 90 & $\%$ \\
\hline
\end{tabular}

The HRSG is a cross-flow heat exchanger as shown in Fig. 2. In the model calculation, the following assumptions are made for the HRSG: (i) the pressure inside both HP and LP steam tubes remains constant without pressure drop; (ii) the radiative heat transfer between the exhaust gas and the steam is neglected; (iii) the exterior part of HRSG is well insulated without heat loss to the environment. To investigate the heat transfer 
characteristic of the HRSG, the overall heat transfer coefficient between the exhaust gas and the steam is determined. On the exhaust gas side, the heat transfer is enhanced by external-finned tubes. The overall surface efficiency can be determined from the fin geometry and fin configuration [14]. On the steam side, the DittusBoelter equation is employed to determine the singlephase heat transfer coefficient of steam [15]. For the two-phase heat transfer coefficient, the Chen correlation for the force convective boiling inside a tube is utilized as follows [16]:

$$
q^{\prime \prime}=h_{T P}\left(T_{w}-T_{s a t}\right)=\left(h_{S P}+h_{N B}\right)\left(T_{w}-T_{s a t}\right)
$$

The two-phase forced convective heat transfer coefficient, $h_{T P}$, is decomposed into $h_{S P}$ and $h_{N B}$ or the single-phase convective heat transfer coefficient and the two-phase nucleate boiling heat transfer coefficient, respectively. The modified Dittus-Boelter equation is used to determine $h_{S P}$. On the other hand, $h_{N B}$ is determined by the modified Forster-Zuber relation [17].

$$
\begin{gathered}
h_{S P}=0.023\left(\frac{k_{l}}{D}\right) R e_{l}^{0.8} \operatorname{Pr}_{l}^{0.4} C F \\
h_{N B}=0.00122\left(\frac{k_{l}^{0.79} c_{p l}^{0.45} \rho_{l}^{0.49}}{\sigma^{0.5} \mu_{l}^{0.29} h_{f g}^{0.24} \rho_{v}^{0.24}}\right) \\
\quad \times\left(T_{w}-T_{\text {sat }}\right)^{0.24}\left(P_{\text {sat }, T w}-P_{\text {sat }}\right)^{0.75} S
\end{gathered}
$$

The modified term in Eq. (2) is the convective boiling factor, $C F$, which can be determined as follows [18]:

$$
C F=2.35\left(\frac{1}{X_{t t}}+0.213\right)^{0.736}
$$

$X_{t t}$ appearing in Eq. (4) is the Martinelli parameter, defined as the pressure drop ratio as follows [19]:

$$
X_{t t}=\left(\frac{1-x}{x}\right)^{0.9}\left(\frac{\rho_{v}}{\rho_{l}}\right)^{0.5}\left(\frac{\mu_{l}}{\mu_{v}}\right)^{0.1}
$$

The modified term in Eq. (3) is the suppression factor, $S$, which can be determined as follows:

$$
S=\frac{1}{1+\left(2.53 \times 10^{-6}\left(\mathrm{CF}^{1.25} \operatorname{Re}_{l}\right)^{1.17}\right)}
$$

It noted that the iterative method is required for the Chen correlation to obtain the heat transfer rate and the temperature difference between the saturation and tube surface temperatures [20]. The technical data for the HRSG including the geometry of the external-finned tubes are given in Table 2.

Table 2. Technical Data of the HRSG (per one gas turbine unit).

\begin{tabular}{llccc}
\hline No. & \multicolumn{1}{c}{ Description } & Symbol & Value & Unit \\
\hline 1 & $\begin{array}{l}\text { HP condensate mass flow rate entering and } \\
\text { leaving the HRSG }\end{array}$ & $m_{H P, S G}$ & 12.18 & $\mathrm{~kg} / \mathrm{s}$ \\
2 & LP condensate mass flow rate entering the & & & \\
& HRSG & $m_{L P, S G i}$ & 10.14 & $\mathrm{~kg} / \mathrm{s}$ \\
3 & LP process-hot-water mass flow rate & $m_{L P, p c}$ & 6.46 & $\mathrm{~kg} / \mathrm{s}$ \\
4 & LP steam mass flow rate leaving the HRSG & $m_{L P, S G}$ & 3.68 & $\mathrm{~kg} / \mathrm{s}$ \\
5 & HP steam pressure at the HRSG & $P S_{H P}$ & 4,400 & $\mathrm{kPa}$ \\
6 & LP steam pressure at the HRSG & $P S_{L P}$ & 400 & $\mathrm{kPa}$ \\
7 & Tube inner diameter for HP steam & $I D_{H P}$ & 26.4 & $\mathrm{~mm}$ \\
8 & Tube outer diameter for HP steam & $O D_{H P}$ & 31.8 & $\mathrm{~mm}$ \\
9 & Tube inner diameter for LP steam & $I D_{H P}$ & 26.4 & $\mathrm{~mm}$ \\
10 & Tube outer diameter for LP steam & $O D_{H P}$ & 31.8 & $\mathrm{~mm}$ \\
11 & Fin thickness & $t_{F}$ & 1 & $\mathrm{~mm}$ \\
12 & Fin length & $L_{F}$ & 12.7 & $\mathrm{~mm}$ \\
13 & Number of fin per tube length & $N_{F}$ & 250 & $\mathrm{~m}{ }^{-1}$ \\
14 & Tube length for HP SH, HP EV, and HP EC2 & & 200 & $\mathrm{~m}$ \\
15 & Tube length for HP EC1 & & 85 & $\mathrm{~m}$ \\
16 & Tube length for LP SH, LP EV, and LP EC2 & & 160 & $\mathrm{~m}$ \\
17 & Tube length for LP EC1 & & 60 & $\mathrm{~m}$ \\
\hline
\end{tabular}

The Rankine cycle depicted in Fig. 1 requires two exit steams generated from both HRSGs. The mixing steam enters the HP steam turbine, at which the work is extracted. Once the steam exits the HP steam turbine, some part of this steam will return back as steam for STIG to one of the gas turbines whereas the remaining is 
used as the HP process steam. Two LP steams after leaving the HRSGs are mixed and sent to the LP steam turbine to extract the work. Thereafter, it will be condensed to condensate and return to the pump. In order to conserve the water/steam mass flow rate of the entire plant, the amount of the makeup water is equal to the summation of the mass flow rates of the HP process steam and the LP process hot water. The condensate after leaving the condenser is assumed to be saturated. Thereafter, it is divided in half and pumped isentropically back to the HRSGs. The technical data used for the thermodynamic analysis of the Rankine cycle are present in Table 3.

Table 3. Technical data of the Rankine cycle.

\begin{tabular}{llccc}
\hline No. & \multicolumn{1}{c}{ Description } & Symbol & Value & Unit \\
\hline 1 & HP steam mass flow rate entering the turbine & $m_{H P, T B i}$ & 24.36 & $\mathrm{~kg} / \mathrm{s}$ \\
2 & LP steam mass flow rate entering the turbine & $m_{L P, T B i}$ & 7.36 & $\mathrm{~kg} / \mathrm{s}$ \\
3 & HP steam mass flow rate leaving the turbine & $m_{H P, T B o}$ & 4.17 & $\mathrm{~kg} / \mathrm{s}$ \\
& for HP process steam and STIG steam & & & \\
4 & LP steam mass flow rate leaving the turbine & $m_{L P, T B o}$ & 27.55 & $\mathrm{~kg} / \mathrm{s}$ \\
& back to the condenser & $P S_{H P, e x i t}$ & 1,200 & $\mathrm{kPa}$ \\
5 & HP steam turbine exit pressure & $P S_{L P, e x i t}$ & 8.65 & $\mathrm{kPa}$ \\
6 & Condensing Pressure & $\eta_{S T}$ & 85 & $\%$ \\
7 & Isentropic efficiency of the steam turbine & & & \\
\hline
\end{tabular}

\section{Solution Procedure}

The parametric investigation of the extracted steam mass flow rate for STIG (msTIG) from the HP steam turbine exit is conducted by varying from 0 to $2 \mathrm{~kg} / \mathrm{s}$ with an increment of $0.25 \mathrm{~kg} / \mathrm{s}$. The amount of the HP process steam $\left(m_{H P, p c}\right)$ will decrease in order to maintain a constant HP steam mass flow rate leaving the steam turbine $\left(m_{\text {HP,TBo }}\right)$ of $4.17 \mathrm{~kg} / \mathrm{s}$, but the energy content, i.e., the enthalpy, of the HP steam at the turbine exit will change according to the state of exhaust gas leaving the gas turbine (state 4 in Fig. 1). This extracted steam is only used for the steam injection at the combustion chamber of the gas turbine cycle 1 whereas the gas turbine cycle 2 is operated without the STIG system. It is noted that, by varying $m_{S T I G}$ from 0 to $2 \mathrm{~kg} / \mathrm{s}$, it is corresponding to 0 to $48 \%$ steam extraction out of $m_{H P, T B o}$ of $4.17 \mathrm{~kg} / \mathrm{s}$. The solution procedure of the proposed model is depicted in Fig. 3.

When the solution converges, the energy transfer behaviors of the cogeneration plant are determined. These include the input energy rate from the fuel $(F)$, the total electrical output power $(P)$, and the output heat rate from steam $(Q)$, which can be written in Eqs. (7-9).

$$
F=m_{f} L H V
$$

$m_{f}$ is the fuel mass flow rate. $L H V$ is the lower heating value of natural gas used for both gas turbines.

$$
P=P_{G T}+P_{S T}=P_{G T 1}+P_{G T 2}+P_{S T}
$$

$P_{G T 1}$ and $P_{G T 2}$ are the electrical output power of the gas turbine cycles 1 and 2, respectively. These two combined become $P_{G T}$. On the other hand, $P_{S T}$ is the electrical output power of the steam cycle. $P_{G T 1}, P_{G T 2}$, and $P_{S T}$ are calculated using the first law of thermodynamics on each device.

$$
Q=m_{H P, p c}\left(i_{H P, p c}-i_{0}\right)+m_{L P, p c}\left(i_{L P, p c}-i_{0}\right)
$$

$m_{H P, p c}$ and $m_{L P, p c}$ are the HP process steam and LP process hot water mass flow rates respectively, which are sent out of the cogeneration plant to the customers in Fig. 1. $i_{H P, p c}$ and $i_{L P, p c}$ are the enthalpy of HP and LP steam exiting the steam turbine respectively. Then, $Q$ is calculated based on the reference enthalpy of water $\left(i_{0}\right)$ at $27^{\circ} \mathrm{C}, 1 \mathrm{~atm}$. After $F, P$ and $Q$ are obtained, the primary energy saving (PES) can be determined as follows [21]:

$$
P E S=1-\frac{1}{\frac{E f f_{P}}{E f f_{P, r e f}}+\frac{E f f_{Q}}{E f f_{Q, r e f}}}
$$

EffP and Effe appearing in Eq. (10) is the cogeneration electrical efficiency and the cogeneration heat efficiency, respectively. Both can be written as

$$
\begin{aligned}
& E f f_{P}=\frac{P}{F} \\
& E_{Q} f_{Q}=\frac{Q}{F}
\end{aligned}
$$

EffP, ref and EffQ,ref appearing in Eq. (10) is the reference electrical efficiency of $45.28 \%$ and the reference heat efficiency of $85 \%$, respectively [7]. 


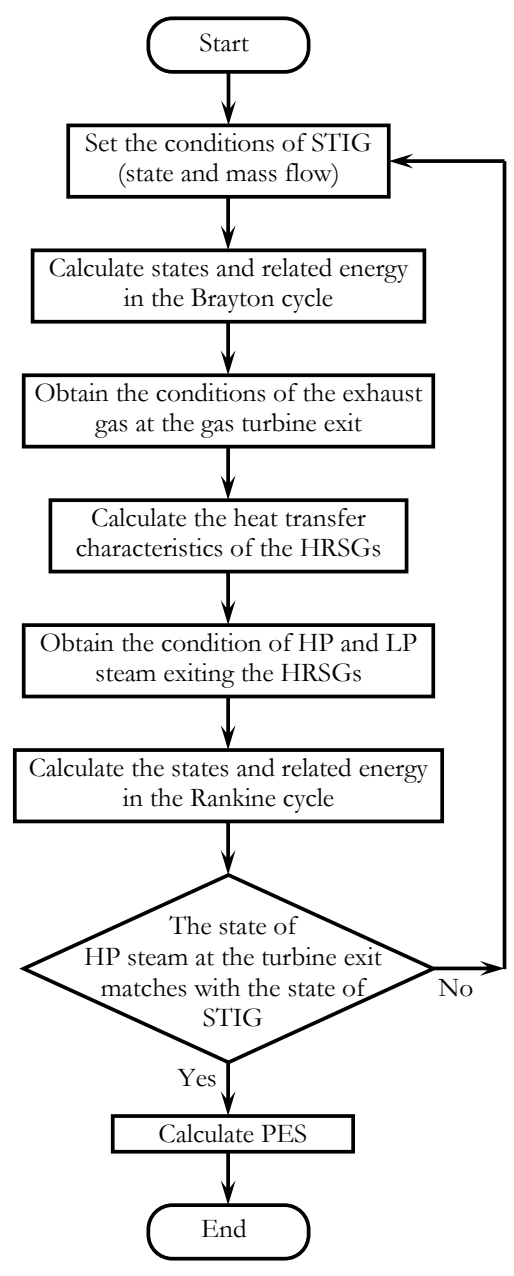

Fig. 3. The flowchart of the solution procedure.

\section{Results and Discussion}

Based on the presented model, the variation of the input energy rate from the fuel $(F)$ with the steam mass flow rate for STIG (mSTIG) is depicted in Fig. 4. It can be seen that the amount of $F$ increases with increasing of $m_{\text {STIG. }}$. Since the temperature exiting the gas turbine $\left(T_{3}\right)$ is fixed at $1,600 \mathrm{~K}$, the input energy rate required at the combustion chamber at the gas turbine cycle 1 is proportional to the total mass flow rate through this combustion chamber itself. As a result of additional injected steam which does not involve in the combustion process, the value of $F$ will be higher. Over the range of STIG steam mass flow rate from 0 to $2 \mathrm{~kg} / \mathrm{s}, F$ is increased by $3.86 \mathrm{MW}$ or $2.00 \%$.

Figure 5 illustrates the variation of the electrical output power from the gas turbines $\left(P_{G T}\right)$ with the steam mass flow rate for STIG. It can be seen that as mSTIG increases from 0 to $2 \mathrm{~kg} / \mathrm{s}, P_{G T}$ is slightly increased by $1.37 \mathrm{MW}$ or $1.92 \%$. The addition STIG mass flow leads to a higher amount of the total mass flow through the gas turbine. Because the power required by the compressor does not change due to the constant air mass flow rate and the constant pressure ratio across the compressor, the net electrical power delivered by the gas turbine increases.
The variation of the electrical output power from the steam turbine $\left(P_{S T}\right)$ with the steam mass flow rate for STIG is depicted in Fig. 6. $P_{S T}$ is slightly increased by $1.65 \mathrm{MW}$ or $6.70 \%$ over the range of mSTIG from 0 to 2 $\mathrm{kg} / \mathrm{s}$. The mass flow of the exhaust gas entering the HRSG will increase due to the additional STIG steam mass flow. The amount of heat transferred from the exhaust gas to both HP and LP steam at HRSG increases. The temperature and the enthalpy of the steam entering the steam turbine will be higher. As a result, the electrical output power extracted from the steam turbine will increase as well.

Figure 7 depicts the variation of the total electrical output power $(P)$ with the steam mass flow rate for STIG. Since $P$ is a combination of $P_{G T}$ and $P_{S T}$, it is increased by $3.02 \mathrm{MW}$ or $3.15 \%$ with increasing $m_{\text {STIG from } 0}$ to 2 $\mathrm{kg} / \mathrm{s}$. With this effect, the STIG system is generally used for a stand-alone combined cycle where the heat from the exhaust gas is considered a waste energy. In a certain situation, the STIG system is used for a sprint mode where an extra output electrical power is required.

The variation of the output heat rate from steam $(Q)$ with the steam mass flow rate for STIG is depicted in Fig.

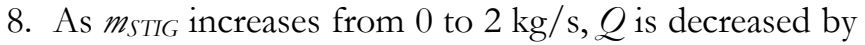
$5.71 \mathrm{MW}$ or $34.9 \%$. According to Eq. 9, the major contribution of $Q$ is the HP process steam with higher enthalpy than the LP process hot water. In case of no $m_{\text {STIG, }}$, the portion of $\mathcal{Q}$ from the HP steam is $11.8 \mathrm{MW}$ out of the total $Q$ of $16.3 \mathrm{MW}$. In case of $m_{S T I G}$ of $2 \mathrm{~kg} / \mathrm{s}$, mass flow rate for the HP process steam $\left(m_{H P, p c}\right)$ is reduced to $2.17 \mathrm{~kg} / \mathrm{s}$ compared with that of $4.17 \mathrm{~kg} / \mathrm{s}$ without mSTIG. Therefore, the portion of $\mathcal{Q}$ from the HP steam is decreased to $6.3 \mathrm{MW}$ out of the total $Q$ of 10.6 MW. The reduction of this is mainly from the use of steam for STIG system.

Figure 9 illustrates the variation of the cogeneration electrical efficiency $\left(E f f_{P}\right)$ with the steam mass flow rate for STIG. According to Eq. 11 and the trends of $F$ and $P$ shown in Figs. 4 and 7, it is noticed that the increase of $P$ over the range of $m_{\text {STIG }}$ is higher than that of $F$. As a result, the value of EffP is slightly increased from $49.9 \%$ to $50.4 \%$. This result indicates that the STIG system will enhance the thermal efficiency of the combined cycle if the generated steam from the waste exhaust gas is used to produce electricity only.

The variation of the cogeneration heat efficiency $(E f f \varrho$ ) with the steam mass flow rate for STIG is depicted in Fig. 10. As we can see in Figs. 4 and 8, the trends of $F$ and $Q$ are in the opposite direction. Thus, the ratio of $Q$ to $F$, i.e., $E_{f 2}$ will highly decrease from $8.5 \%$ to $5.4 \%$. By combining the effect of EffP shown in Fig. 9, it is indicated that for the cogeneration plant, the STIG system trades the benefit of the higher electrical efficiency with the lower heat efficiency.

Figure 11 depicts the variation of the primary energy saving (PES) with the steam mass flow rate for STIG. As mentioned earlier, the value of PES represents the saving energy provided by the cogeneration plant compared to the energy provided by an individual 
electrical power plant and individual process heating plant. Since the trends of EffP and Effe are in an opposite direction with the change of mSTIG, the value of PES presents the overall effect of mSTIG on the performance of the cogeneration plant. From Fig. 11, the effect of the change of EffP is offset by that of Effe, leading to the reduction of PES. It is increased from $16.6 \%$ to $14.9 \%$ with increasing $m_{\text {STIG }}$ from 0 to $2 \mathrm{~kg} / \mathrm{s}$.
In practice, it is recommended to utilize the STIG system when more electrical load is required with the partial thermal load simultaneously. Based on the power purchase agreement [7], the value of PES should be maintained above $10 \%$ to achieve the maximum feed-in tariff. As a result, the implementation of the STIG system should be carefully employed to keep PES above $10 \%$.

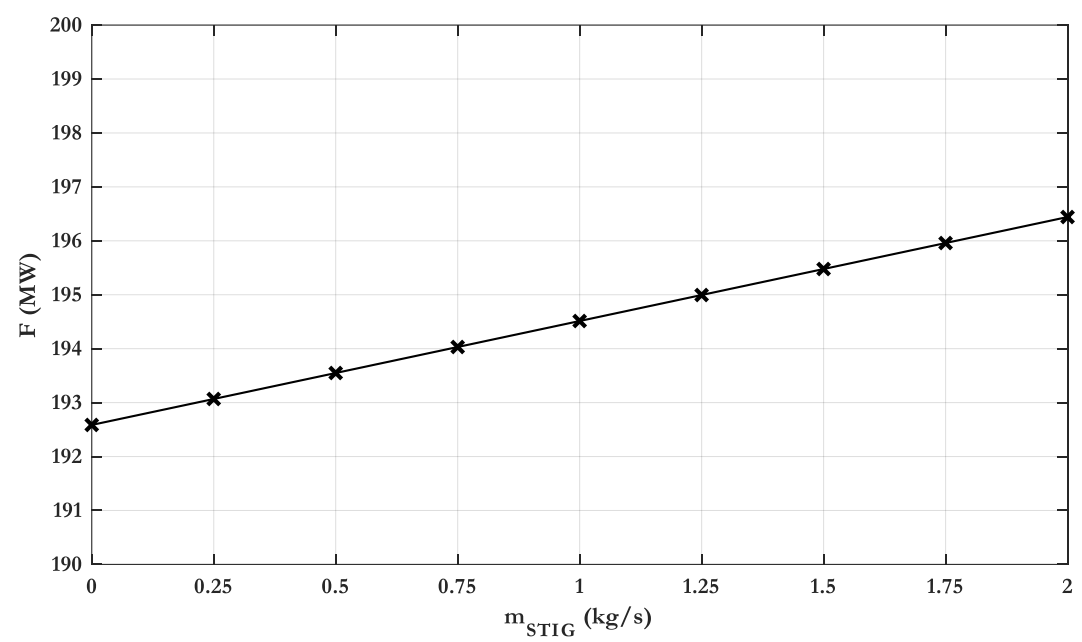

Fig. 4. Variation of the input energy rate from the fuel with the steam mass flow rate for STIG.

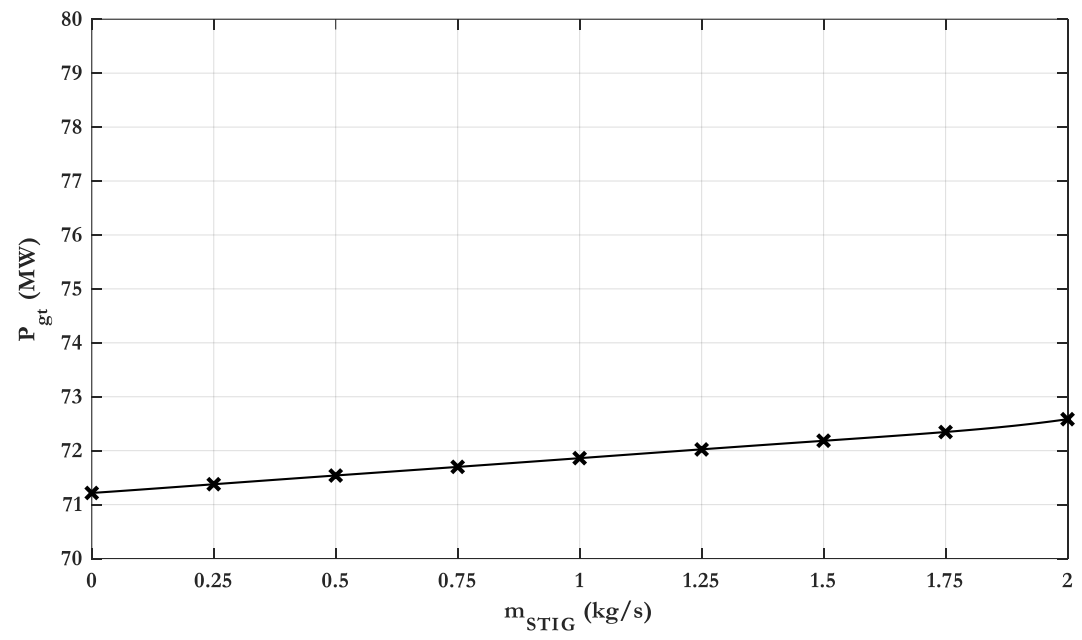

Fig. 5. Variation of the electrical output power from the gas turbines with the steam mass flow rate for STIG. 


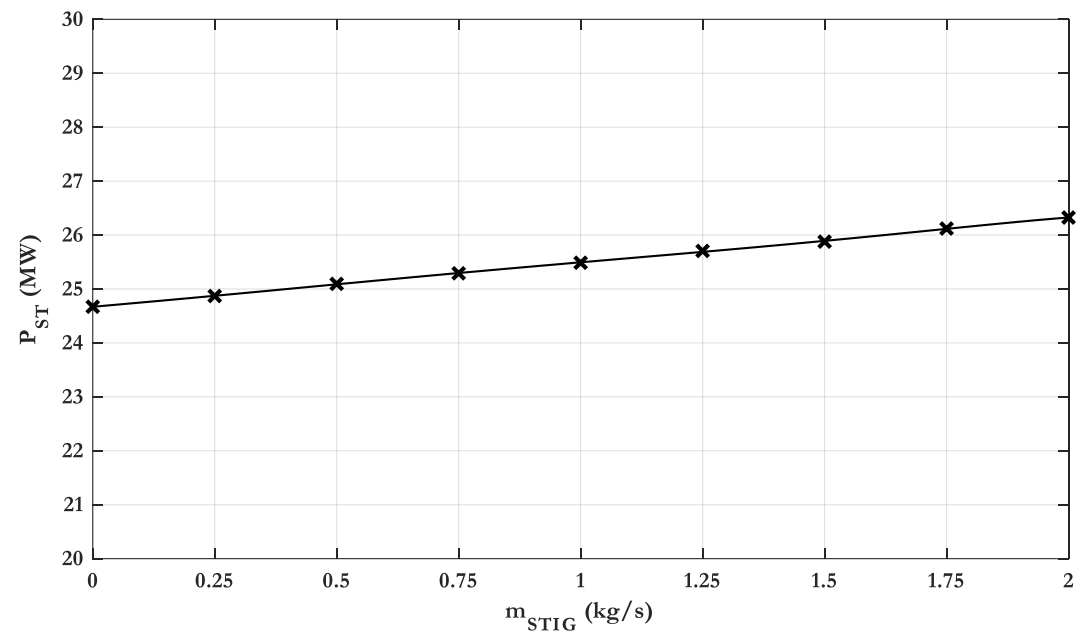

Fig. 6. Variation of the electrical output power from the steam turbine with the steam mass flow rate for STIG.

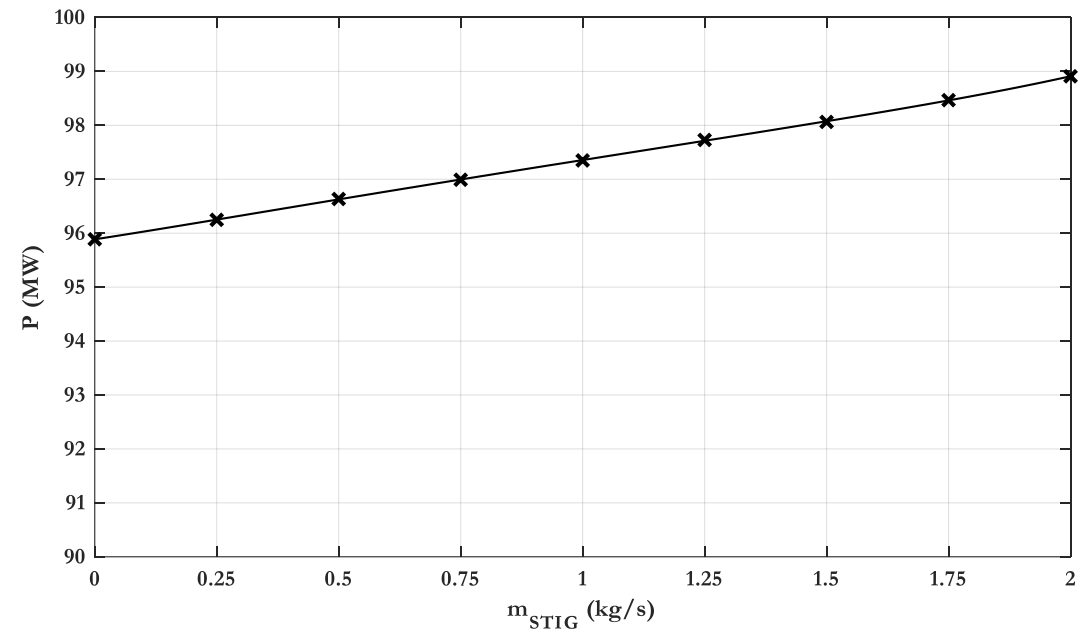

Fig. 7. Variation of the total electrical output power with the steam mass flow rate for STIG.

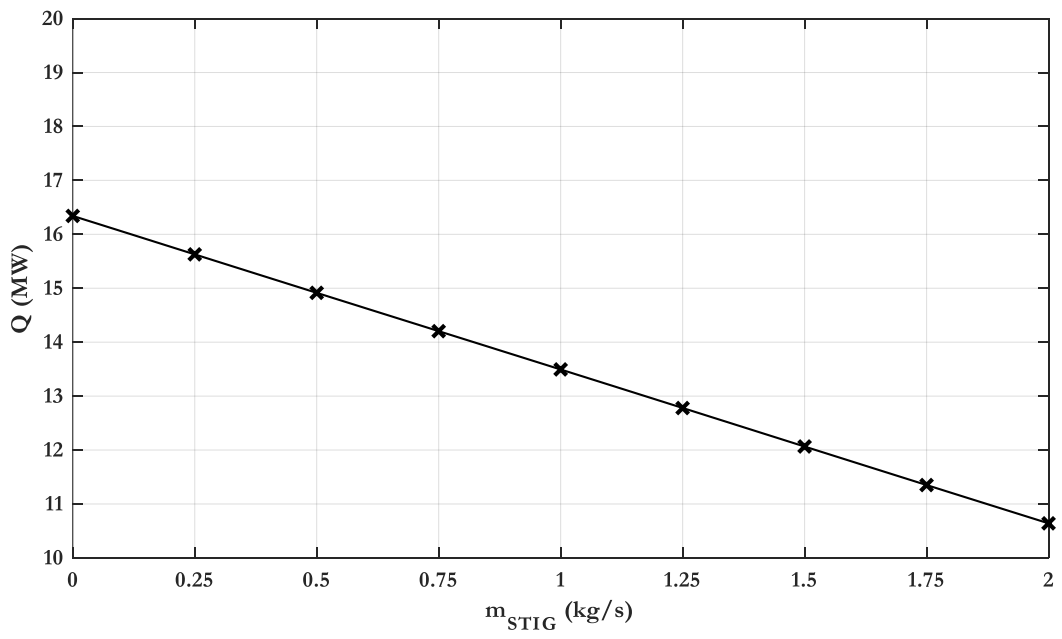

Fig. 8. Variation of the output heat rate from steam with the steam mass flow rate for STIG. 


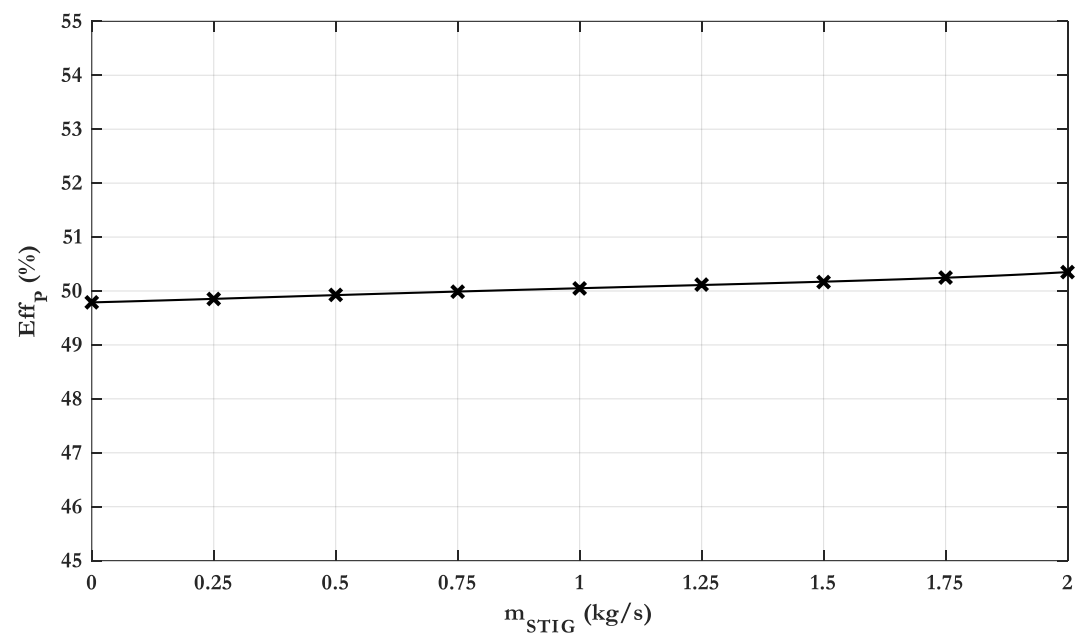

Fig. 9. Variation of the cogeneration electrical efficiency with the steam mass flow rate for STIG.

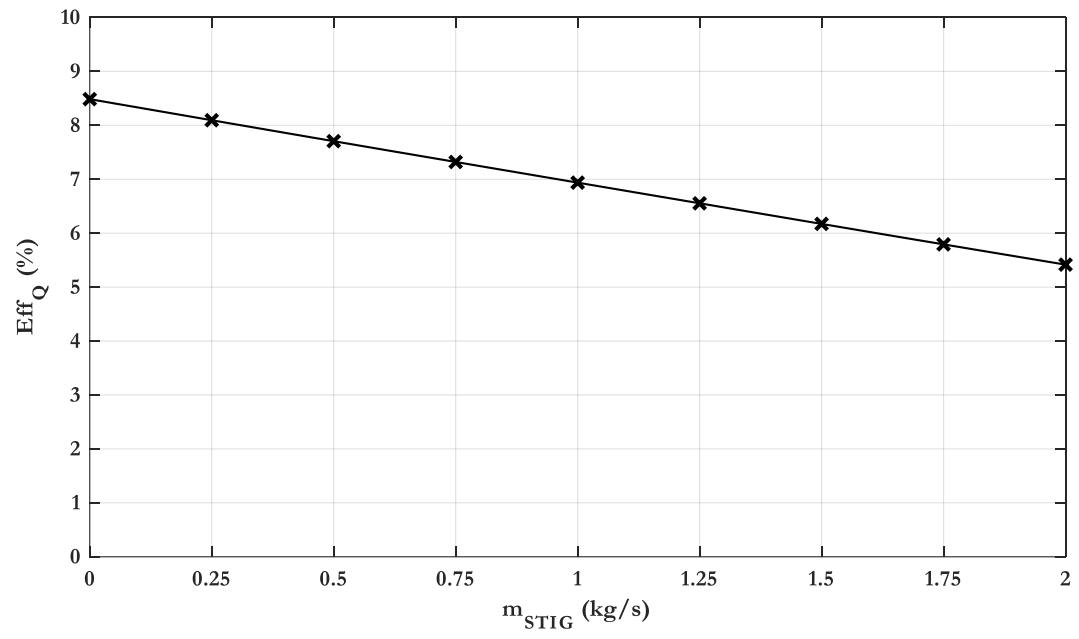

Fig. 10. Variation of the cogeneration heat efficiency with the steam mass flow rate for STIG.

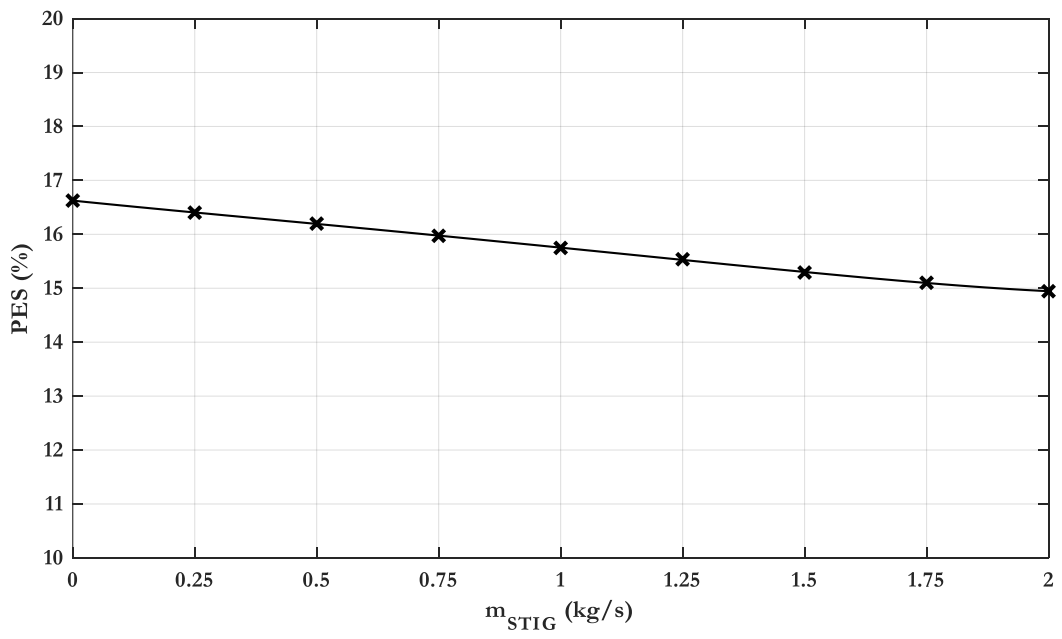

Fig. 11. Variation of the primary energy saving with the steam mass flow rate for STIG. 


\section{Conclusions}

A parametric investigation of the steam mass flow rate for STIG on the PES of the cogeneration plant is performed in this present study. The thermodynamic model of both gas turbine cycles and a steam-turbine cycle, together with the heat transfer model of HRSG, is developed. The effects of the steam mass flow rate for STIG varied from 0 to $2 \mathrm{~kg} / \mathrm{s}$ on the energy transfer behaviors of the cogeneration are presented. The results indicate that the input energy rate from the fuel and the total electrical output power from the cogeneration plant are increased with increasing steam mass flow rate for STIG. The total electrical output power is increased at a higher portion than the input energy rate from the fuel, leading to an increase of the cogeneration electrical efficiency from $49.9 \%$ to $50.4 \%$. On the other hand, the output heat rate from the steam is decreased with increasing steam mass flow rate for STIG, leading to a decrease of the cogeneration heat efficiency from 8.5\% to $5.4 \%$. The primary energy saving of the cogeneration plant decreases from $16.6 \%$ to $14.9 \%$. Because the value of PES is higher than $10 \%$, the implementation of the STIG system within this range is still applicable for a sprint mode in case of the need for additional electrical power and the reduction of heating demand.

\section{References}

[1] Ministry of Energy, Thailand, Energy Policy and Planning Office, "Thailand power development plan 2015-2036," pp. 2-4, 2015.

[2] D. Gvozdenac, C. Menke, P. Vallikul, J. Petrovic, B. Gvozdenac, "Assessment of potential for natural gas-based cogeneration in Thailand," Energy, vol. 34, pp. 465-475, 2007.

[3] W. Somcharoenwattana, C. Menke, D. Kamolpusb, and D. Gvozdenac, "Study of operational parameters improvement of natural-gas cogeneration plant in public buildings in Thailand," Energy and Buildings, vol. 43, pp. 925-934, 2011.

[4] K. Manusilpa and D. Banjerdpongchaib, "Analysis of multi-objective optimal dispatch of cogeneration with thermal energy storage for building energy management system," Engineering Journal, vol. 21, no. 5, pp. 67-79, 2011.

[5] Eurostat. (n.d.). Combined Heat and Power (CHP) Generation [Online]. Available: http://ec.europa.eu/ eurostat/documents/38154/42195/Final_CHP_re porting_instructions_reference_year_2016_onwards _30052017.pdf/f114b673-aef3-499b-bf38-

f58998b40fe6 [Accessed: 10 July 2018]

[6] C. A. Frangopoulos, "A method to determine the power to heat ratio, the cogenerated electricity and the primary energy savings of cogeneration systems after the European Directive," Energy, vol. 45, no. 1, pp. 52-61, 2012.

[7] Electricity Generating Authority of Thailand. (2007). Power Purchase Agreement for Small Power Producer
(Cogeneration) [Online]. Available: http://www.ppa.egat.co.th/sppx/images/SPP_Doc ument/Regulation/Firm

Cogen/Reg_FirmCogen_53(54).pdf [Accessed: 10 July 2018]

[8] Y. S. H. Najjar, "Gas turbine cogeneration systems: A review of some novel cycles," Applied Thermal Engineering, vol. 20, pp. 179-197, 2000.

[9] O. Boland and J. F. Stadaas, "Comparative evaluation of combined cycles and gas turbine systems with water injection, steam injection and recuperation," in The International Gas Turbine and Aeroengine Congress and Exposition, Cincinnati, Ohio, May 24-27, 1993, paper no. 93-GT-57.

[10] T. Korakianitis, J. Grantstrom, P. Wassingbo, and A. F. Massardo, "Parametric performance of combined-cogeneration power plants with various power and efficiency enhancements," Journal of Engineering for Gas Turbines and Power, vol. 127, no. 1, pp. 65-71, 2005.

[11] E. Macchi and A. Poggio, "A cogeneration plant based on a steam injection gas turbine with recovery of the water injected: Design criteria and initial operating experience," in The International Gas Turbine and Aeroengine Congress and Exposition, The Hague, Netherlands, June 13-16, 1994, paper no. 94-GT-017.

[12] M. G. Soufi, T. Fujii, and K. Sugimoto, "A modern injected steam gas turbine cogeneration system based on exergy concept," International Journal of Energy Research, vol. 28, no. 13, pp. 1127-1144, 2004.

[13] KTH Royal Institute of Technology. (n.d.). Steam Injection Gas Turbine [Online]. Available: http://www.energy.kth.se/compedu/webcompedu /WebHelp/media\%5CPrint\%5Cs1b5c1_A4.pdf [Accessed: 12 July 2018]

[14] F. P. Incropera, D. P. DeWitt, T. L. Bergman, and A. S. Lavine, "One-dimensional, steady-state conduction," in Fundamentals of Heat and Mass Transfer, 6th ed. Singapore: John Wiley \& Sons, 2007, ch. 3, sec. 3-6, pp. 147-155.

[15] Y. Cengel, "Internal forced convection," in Heat and Mass Transfer: A Practical Approach, 3rd ed. Singapore: McGraw Hill, 2006, ch. 8, sec. 8-6, pp. 473-474.

[16] J. C. Chen, "Correlation for boiling heat transfer to saturated fluids in convective flow," Industrial \& Engineering Chemistry Process Design and Development, vol 5, no. 3, pp. 322-329, 1966.

[17] H. K. Forster and N. Zuber, "Dynamics of vapor bubbles and boiling heat transfer," AIChE Journal, vol. 1, no. 4, pp. 531-535, 1955.

[18] M. M. Mahmoud and T. G. Karayiannis, "Heat transfer correlation for flow boiling in small to micro tubes," International Journal of Heat and Mass Transfer, vol. 66, pp. 553-574, 2013.

[19] J. G. Collierand J. R. Thome, "Saturated boiling heat transfer," in Convective Boiling and Condensation. UK: Oxford University Press, 1996, ch. 7, sec. 7.3, pp. 253. 
[20] M. N. Ozisik, "Boiling and condensation," in Heat Transfer: a Basic Approach. Singapore: McGraw Hill, 1985, ch. 10, sec. 10-8, pp. 505-513.

[21] Energy Regulatory Commission. (n.d.). A Manual of Auditing of the Cogeneration System Efficiency and PES
Calculation for a Small Power Producer [Online]. Available:

https://www.erc.or.th/ERCWeb2/EN/Default.asp x [Accessed: 12 July 2018]

Phongthon Buntarikpornpant, photograph and biography not available at the time of publication.

Chittin Tangthieng, photograph and biography not available at the time of publication. 